\title{
O processo emancipatório dos atores sociopolíticos no constitucionalismo latino-americano
}

\section{The emancipatory process of the sociopolitical actors at the latin american constitutionalism}

\author{
Rene José Keller \\ Mestre em Direito (UCS) \\ rene.keller07@gmail.com
}

\begin{abstract}
Resumo: O novo constitucionalismo latino-americano apresenta um cenário de forte questionamento das instituições tradicionais da política, da economia e do Direito, visto que já proporcionou refundações constitucionais (Equador - 2008 e Bolívia - 2009). O artigo objetiva reunir elementos para apresentar possíveis respostas às seguintes perguntas: (i) há um processo emancipatório em curso no novo constitucionalismo latino-americano?; (ii) quais subjetividades coletivas preponderam nesse contexto? Adotando-se como referencial teórico-metodológico a dialética materialista, verifica-se que o desenvolvimento do capitalismo nos séculos XX e XXI, especialmente nos países latino-americanos, parece ter reconfigurado o eixo emancipatório da questão do trabalho, modelando subjetividades não necessariamente vinculadas ao labor. Portanto, a compreensão do processo de transformação que está em curso na América Latina deve ser precedida de um exame dos seus sujeitos e das suas plataformas, instigando em que medida corroboram à emancipação humana nos termos formulados pelos fundadores da filosofia da práxis.
\end{abstract}

Palavras-chave: Emancipação. Sujeitos coletivos. Constitucionalismo latino-americano. Indígena. Proletário.

\begin{abstract}
The new Latin American constitutionalism presents a scenario that has a strong questioning of traditional institutions such as the politics, economics and law fields, that has already provided constitutional reformulations (Ecuador - 2008 and Bolivia - 2009). The article aims to gather evidence to present possible answers to the following questions: (i) is there an emancipatory process in the new Latin American constitutionalism?; (ii) which collective subjectivities predominate in this context? Adopting the materialist dialectics as a theoretical and methodological framework, it appears that the development of capitalism in the twentieth and twenty-first centuries, especially in Latin American countries, seems to have reconfigured the emancipatory axis of issue of labor, creating social actors not necessarily linked to the labor question. Therefore, understanding the process of transformation that is taking place in Latin America should be preceded by an examination of their subjects and their platforms, prompting in what extent they corroborate to the human emancipation in terms formulated by the founders of the philosophy of praxis.
\end{abstract}

Keywords: Emancipation. Collective subject. Latin american constitutionalism. Indigenous. Proletarian.

Originais recebidos em: 23/03/2014

Aceito para publicação em: 27/06/2014

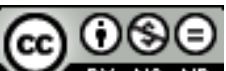

Comercial-Vedada a criação de obras derivadas 3.0 Unported License. 


\section{Introdução}

Rompendo com a tradição regional de importar, no mais das vezes cegamente, o Direito a ser aplicado nos mais diversos países da América Latina, o novo constitucionalismo latino-americano rompeu com subserviência intelectual até então comum, girando a lente jurídica às suas crenças regionais e atentando à sua formação social peculiar. Emana das legislações principalmente da Bolívia e do Equador uma concepção diversa daquela adotada nos países de cultura ocidental. O constitucionalismo latino-americano propõe a organização da sociedade pautada no "bem viver", na relação harmônica da pessoa com a natureza, igualmente, essa ideia de um viver bem se encontra inserida no contexto de um ideal de sociedade a qual se pretende construir, rompendo com a lógica do capital.

Ainda que se possa examinar o fenômeno do constitucionalismo latinoamericano recente por diversos prismas de análise, um dos principais caminhos para compreender determinada opção constitucional é examinando as práticas sociais que embasaram a sua consolidação. Isto é, analisar quais foram as correlações de forças que se estabeleceram de modo a ofertar uma maior ou menor ruptura com a ideologia capitalista, cujo reflexo se deu também no campo do Direito, o qual se afastou de teorias eurocêntricas e norte-americanas de cunho liberal e/ou idealistas.

Imbuído da missão de investigar o constitucionalismo latino-americano a partir dos atores sociais de mudança, o presente estudo, calcado no método dialético materialista, em um primeiro estágio pretende demonstrar como houve na teoria marxiana tradicional uma superestimação da potencialidade revolucionária do proletário, bem como o esfacelamento da consciência de classe como opção de estratégia política. Estes dois aspectos, por si, ensejam uma grande reflexão acerca dos exageros teóricos procedidos por quem se avoca do marxismo, não obstante aqui se construa uma crítica externa, já que o instrumental teórico é amplamente utilizado e chancelado. Esse ponto guarda grande relevância ao constitucionalismo latino americano, ao passo que se levanta a hipótese de que não pode ser encarado como um levante tipicamente do trabalhador, aos moldes cunhados pelo marxismo tradicional.

Uma vez perpassada a crítica à mitificação do proletário como sujeito revolucionário, que consubstancia em premissa necessária para avançar no estudo, examina-se como os atores sociais latino-americanos atuam no seu processo emancipatório, rompendo com o fatalismo imposto por alguns autores da vertente 
crítica. Muito embora muitos deles tenham superado a visão do proletário com sujeito revolucionário, tão somente substituíram o personagem, como se sempre houvesse alguma coletividade capaz de ser agrupada e nomeada, com forças hábeis para conduzir o processo revolucionário. Portanto, é preciso investigar onde se situa os atores sociais latino-americanos dentro do curso emancipatório deste constitucionalismo, ao mesmo instante em que se procede uma crítica às formações teóricas tradicionais do marxismo que não dão conta de apreender o fenômeno que se defronta.

Atenta-se, por oportuno, que o uso de literatura que escapa por completo da seara jurídica será habitual, tendo em vista que o fenômeno jurídico não pode ser entendido, sob o enfoque proposto, como autopoiético, também como forma de melhor apreender o objeto. Ademais, como não se pretende elaborar um estudo normativo, não haverá referência explícitas aos artigos das Constituições que se analisa, tendo em vista que parece ser justamente aí que se encontram a maior parte dos estudos jurídicos que abordam o tema, preferindo uma análise voltada à base social que formou as referidas legislações.

\section{A superestimação da potencialidade revolucionária do proletário fabril e o esfacelamento da consciência de classe}

Karl Marx destinou ao proletário o encargo de reescrever completamente a história da humanidade, balizada por uma incessante luta de classes, cujo estágio atual se desenvolvendo entre os trabalhadores e a burguesia. Marx não inventou, sequer conceitualmente, as classes sociais ou a luta de classes, descobertas que atribui serem de historiadores e economistas burgueses. A sua inovação teria ocorrido nos seguintes pontos: a) a demonstração que a existência de classes está imbricada a determinadas fases de desenvolvimento histórico da produção; b) a luta de classes conduz necessariamente à ditadura do proletariado; c) que esta ditadura constitui fase transitória à superação de todas as classes e para a consolidação de uma sociedade sem classes (MARX, 1982, p. 555).

O papel direcionado ao proletário foi bem delineado em "A Sagrada Família", estudo que acabou condicionando o pensamento marxiano futuro:

Não se trata do que este ou aquele proletário, ou até mesmo do que o proletariado inteiro pode imaginar de quando em vez como sua meta. Tratase do que o proletário é e do que ele será obrigado a fazer historicamente de 
acordo com o seu ser. Sua meta e sua ação histórica se acham clara e irrevogavelmente predeterminadas por sua própria situação de vida e por toda a organização da sociedade burguesa atual (MARX, ENGELS, 2013, p. 49).

Ao apostar todas as fichas no proletário como sujeito redentor da humanidade, a formação da sua consciência passa a ser necessidade de primeira ordem. A consciência de classe é a condição de autolibertação dos proletários, devendo ser desenvolvida por eles em primeira pessoa, não devendo partir de "cima", a exemplo do que propunham os socialistas utópicos. Nas palavras de Engels (1985, p. 168):

Levar a cabo esta acção libertadora do mundo é a vocação histórica do proletário moderno. Aprofundar as suas condições históricas, e assim a sua própria natureza, e deste modo levar a classe chamada à acção, a classe hoje oprimida, à consciência das condições e da natureza da sua própria acção, é a tarefa da expressão teórica do movimento proletário, do socialismo científico.

Em certo sentido, a vasta proletarização, experimentada nos anos que sucederam a revolução industrial, possibilitou ao socialismo científico assumir relevância nas lutas sociais dos trabalhadores. Ocorre que, a história não permite fatalismos de toda a ordem. Herbert Marcuse (1972, p. 193-196), em uma conferência proferida em 1966, havia alertado à superestimação do potencial revolucionário da classe trabalhadora. $\mathrm{Na}$ ocasião, Marcuse explanou a tese de que o conceito marxista de revolução estava baseado na existência de uma classe que, além de desumanizada e empobrecida, não poderia ter nenhum interesse em comum ao sistema capitalista. Para o autor, a passagem do capitalismo ao socialismo atende a uma moldura global, em que, além de existir um crescente nível de vida nos países industriais avançados, a manipulação científica das necessidades, por meio da publicidade, age como fator de bloqueio da transição, que deixa de ser almejada pelo trabalhador assalariado.

Alguns fatores pesam para que se rompa o fatalismo histórico imposto à classe operária. Os agentes das relações econômicas, em Marx e Engels, são compreendidos dentro de um processo de severa indução, acompanhando o movimento essencial de desenvolvimento das forças produtivas (segregação entre os produtores dos meios de produção). Isso implica na configuração social projetada em dois largos grupos identitários, quais sejam, a classe da burguesia e a dos trabalhadores assalariados. Toda a classe trabalhadora é vista como uma unidade, ainda que o potencial revolucionário estivesse ancorado no trabalhador industrial.

O imperativo de aglutinar o proletário, de modo a convertê-lo em uma força política devastadora e revolucionária, fez com que o pensamento marxiano suprimisse estratificações intermediárias tanto de sujeitos como de demandas. Todavia, dentro de 
uma mesma classe é possível (e até mesmo inevitável) que haja interesses díspares, ao ponto de não haver significativos pontos de identificação recíproca. Essa desagregação classista interna tem, como um dos fatores, a melhora objetiva da situação da classe trabalhadora, mesmo em países dependentes como o Brasil. ${ }^{1}$

A divisão em duas grandes classes, materializada na dicotomia entre o proletário e o burguês, perdeu a sua evidência superestrutural quando deixou de captar as sutilezas que movem o processo real de identificação recíproca. Com a individualização, o consumo, a busca de projeções pessoais ideologizadas de acordo com um ideal de vida burguês etc., houve uma crescente dispersão de consciência da classe trabalhadora, não denotando este conceito uma unidade sequer de reconhecimento intersubjetivo.

Admitindo que este tema foi pouco desenvolvido na teoria marxiana, István Mészarós (2012, p. 1036-1037) assume a existência de forças sociais multifacetadas, portadoras de interesses e objetivos próprios. Ainda assim, as pressupõe como passíveis de junção para ações coordenadas, desde que a unidade não seja imposta "de cima". Ora, o que se questiona sequer é a possibilidade de formação de consenso dentro de uma mesma classe - tarefa em si difícil de ser cumprida -, senão a falta de interesse de pertencimento do trabalhador à respectiva classe.

Insistir para que o trabalhador reconheça a sua condição de classe subalterna, representa, hoje, convencê-lo a abandonar a sua fachada ideologizada e o seu anseio de ser burguês, para que assuma o que se supõe ser a sua verdadeira tarefa existencial. Significa, em outros termos, desmontar por completo o cenário, a peça, a sua encenação na vida cotidiana, para detrás da representação encontrar a pretensa essência universal cuja vocação é a emancipação da humanidade.

Michel Löwy (2012, p. 44) destaca que o mito de um salvador supremo aparece na maior parte das doutrinas políticas: Maquiavel enaltecia o "príncipe", Hobbes o "Soberano Absoluto", para Voltaire o "déspota esclarecido" assume a tarefa, em Rousseau era o "legislador", os Jacobinos o viam no "Incorruptível" e os bonapartistas no "Imperador" etc. Löwy ignora, no entanto, que esse apelo a um herói superior também se fez presente na obra de Karl Marx, sendo o proletário o personagem redentor. A mitificação do proletário acompanha Marx (2006, p. 156) desde idade

\footnotetext{
${ }^{1}$ Ilustrativamente, quase todas as reivindicações reformistas colocadas no II Congresso do Partido Socialista Brasileiro, em 1902, foram gradativamente atendidas: a) jornada de oito horas diárias; b) limitação do trabalho noturno; c) educação obrigatória e gratuita aos menores de quatorze anos; d) criação de tribunais arbitrais para solver disputas entre patrões e empregados; e) adoção do divórcio; f) justiça rápida e gratuita; g) igualdade política para ambos os sexos; h) direito e liberdade de greve; i) preferência para liquidação de salários em caso de falência etc. (LINHARES, 1977, p. 43).
} 
intelectual tenra, nos idos de 1844, fase que já se encontrava plenamente convencido da tarefa natural da classe trabalhadora, que era destituir o burguês do trono: "Quando o proletariado anuncia a dissolução da ordem social existente apenas declara o mistério da sua própria existência, uma vez que é a efetiva dissolução desta ordem".

A forma incisiva com a qual Marx e Engels creditaram ao proletário não somente a sua emancipação, cabendo redimir toda a humanidade, fez com que grande parte da esquerda revolucionária dirigisse a sua ação na tarefa de concatená-lo e auxiliálo para o esclarecimento da sua situação. Jacob Gorender, sem romper com o marxismo, procurou traçar um paralelo entre as teses marxianas e a resposta prática, defendendo o audacioso argumento de que "No caminho da utopia à ciência, Marx e Engels ficaram no meio do trajeto". Sustentou que a classe trabalhadora é ontologicamente reformista, propugnando que o antagonismo social engendrado pela burguesia conduz o proletário a lutar por melhorias dentro das raias do capitalismo. Não há, nas lutas dos trabalhadores, nenhum movimento no sentido de transcender à exploração, ao passo que "O proletariado não constitui um corpo estranho na estrutura socioeconômica burguesa, porém a integra normalmente" (GORENDER, 1999, p. 38-39).

A mitificação do proletário, concedendo-lhe o título de sujeito redentor da humanidade, desconsidera o próprio processo material de transformação da sociedade descrito por Marx e Engels. A classe burguesa não poderia existir sem que tivesse, previamente, revolucionado os instrumentos de produção e, por conseguinte, as relações de produção, resultando em uma completa reconfiguração social. Somente há a mudança de personagem principal e, por conseguinte, revolucionamento social, quando novas forças materiais entram em contradição com as formas até então existentes. Nesse sentido, o burguês foi alçado a esta posição quando abandonou o seu personagem antigo (de vassalo) e dissolveu, através da luta de classes, a configuração social anterior. O proletário, por sua vez, não precisaria abandonar a sua veste de trabalhador para ser projetado ao papel principal, bastava organizar-se e lutar para proceder a um "gap", passando de classe oprimida à classe dominante. ${ }^{2}$

Inexiste na teoria da revolução marxiana uma terceira classe que desponta para decompor a ordem existente. É historicamente contratendencial que uma classe

\footnotetext{
${ }^{2}$ Há uma espécie círculo vicioso, percebido também por Marcuse, quando o autor apontou: “[...] para desenvolver novas necessidades revolucionárias, devem preliminarmente ser removidos os mecanismos que tendem a reproduzir as velhas, o que pressupõe, por sua vez, a necessidade dessa remoção preliminar. Mas, nesse ponto, deparamo-nos com um inegável circulo vicioso, do qual não sei como se possa sair". (MARCUSE, 1969, p. 43).
}

Em Debat: Rev. Dig., ISSNe 1980-3532, Florianópolis, n. 9, p. 40-55, jan-jun, 2013. 
dominada ascenda ao status de dominante. Não se pretende, aqui, explorar uma espécie de fatalismo negativo, no sentido de que a falta de experiência invalide a teoria marxiana da revolução, no entanto, tampouco se pode afirmar, cabalmente, qual é o ser ontológico de uma classe. Jacob Gorender defendia que a classe trabalhadora era ontologicamente reformista, enquanto Marx, em prisma exponencialmente diverso, sustenta a sua ontologia revolucionária. Mesmo que a história tenha dado mais acuidade às palavras de Gorender, a limitação revolucionária jamais é de ordem genética, senão política e de correlação de forças. O que não se pode apostar é que a consciência de classes, quando e se atingida, irá rebentar a humanidade de uma vez por todas. Tampouco não se pode crer, sem nenhuma gota de incerteza, que a tarefa messiânica do trabalhador assalariado é a revolução, sendo este o ponto de chegada inevitável.

Assim como Marx (2010, p. 39; 46), acertadamente, criticou Bruno Bauer quando este propugnou que não se deveria confundir a emancipação política com a humana, aqui, deve-se repreender Marx com a sua própria estrutura argumentativa. Não se deve confundir a emancipação do trabalhador com a emancipação humana. Karl Marx, evidentemente, queria acelerar o processo de evolução histórica ao compreender o seu mecanismo de funcionamento, todavia, embebedou-se com altas doses de otimismos ao defender que a burguesia já havia desenvolvido plenamente as forças produtivas, estando apta a sua superação.

O capitalismo não demonstra nenhum indício de maturação completa, tampouco se verifica alterações substanciais nas forças materiais existentes que sejam capazes de implicar em uma alteração significativa no modo de produção. Jacob Gorender (1999, p. 16) parece ter bem diagnosticado os motivos de tamanho exagero teórico: "A expectativa de realização de um ideal revolucionário não pode ser postergada para além da vida do revolucionário". A defesa cega da gasta dialética entre o proletário e o burguês parece ostentar o seu quinhão de surrealismo, ante ao congelamento da imagem em que há uma disputa real entre esses dois sujeitos, historicamente conflituosos.

Enquanto a esquerda pronuncia a vanguarda do proletário, este sequer clama por uma representação desta estirpe. A leitura acrítica das projeções marxianas conduz à repetição somática da existência perene de uma luta de classes verticalizada e infraestrutural. Não se pode confundir o inegável antagonismo de classes, derivado da efetiva divisão social, com o duelo real em si. A luta de classes pressupõe que apenas uma delas triunfará, enquanto a dualidade classista tem acompanhado a história da humanidade em seus mais distintos momentos. 
O próprio projeto político de suplantação do capitalismo não pode ser tratado com viés fatalista. Ainda que se compreenda sob o ponto de vista estratégico levantar "slogans" como "socialismo ou barbárie", jamais existe caminho seguro na história. O proletário não necessariamente irá suplantar o burguês, assim como tampouco se pode crer que o socialismo venha a suprassumir, por naturalidade, a ordem capitalista. Mais uma vez, Jacob Gorender (1999, p. 233-234) demonstra a maturidade intelectual ao preceituar:

\begin{abstract}
O socialismo não é um fim imanente à sociedade e à sua história, mas um fim que os próprios homens elaboram, sujeito a se realizar ou não. Se as condições objetivas impessoais são, num grau variável, determinadas e determinantes, a realização dos fins, que os homens se propõem, inclusive do fim socialista, estará sempre sujeita à indeterminação, dependente da luta dos próprios homens. [...] Incerteza que faz da luta pelo socialismo uma escolha pela qual são responsáveis, moral e politicamente, os agentes da escolha.
\end{abstract}

O proletário mistificado, vislumbrado pela mágica possibilidade adquirir bens, de projetar-se idealmente e visualmente como um pequeno burguês, rompe com a sua estigma classista. Por mais que estruturalmente permaneça, efetivamente, integrando uma classe de despossuidores oprimidos, os trabalhadores abrigam-se no espetáculo, que nada mais é do que "a afirmação da aparência e a afirmação de toda vida humana isto é, social - como simples aparência” (DEBORD, 2012, p. 16).

A mitificação do proletário e a pregação da sua inequívoca consciência de classe se converteram nas maiores idealismos marxianos, no sentido conferido pelos próprios fundadores para se afastar de Hegel. Não importa a forma como os trabalhadores se apresentam, o seu pensar condicionado, as suas mistificações, suas aspirações burguesas etc., a certeza da sua missão histórica não abala a dura convicção dos marxistas. Proclamar que o proletário quer ser burguês, ao marxista ortodoxo ao estilo de Mészáros, é uma completa heresia nos moldes bíblicos. O autor húngaro condena a aproximação classista: "Devido ao antagonismo estrutural entre capital e trabalho, qualquer discurso sobre a 'integração' ou 'aburguesamento' do proletário [...] é uma contradição nos termos, não importa que tipo de intenção política possa estar por trás disso" (MÉSZÁROS, 2011, p. 68).

Há uma sobrelevação da essência fundante do capitalismo, ignorando-se o exame dos fenômenos, esfera em que se realiza a vida de todos os dias. Ainda que a tarefa metodológica do materialista seja, efetivamente, conectar a ponta visível da realidade com a ideologicamente obscura, não se pode menosprezar nenhum dos lados. O reconhecimento dos avanços e retrocessos no processo histórico de emancipação da 
classe trabalhadora deve ser precedido de um exame acurado do cotidiano. Essa posição de ler a história de modo estático, congelando preceitos de alguma maneira válidos no século XIX, não tem contribuído para a atualização e permanência hígida da dialética materialista como método revolucionário de conhecimento da realidade à transformação.

Por mais romântico e atrativo que seja o discurso emancipatório, deve-se, inevitavelmente, indagar: onde estão os pulmões inquietos dos proletários para soprarem o vento avassalador da revolução? O diagnóstico dado por Marcuse (1967, p. 16) deve ser duramente assimilado:

Na falta de agentes e veículos de transformação social, a crítica é, assim, levada a recuar para um alto nível de abstração. Não há campo algum no qual teoria e prática, pensamento e ação se harmonizem. Até mesmo a análise mais empírica das alternativas históricas parece especulação irreal, e a adesão a ela uma questão de preferência pessoal (ou grupal).

O esfalecimento da consciência de classe acompanha a vitória da indústria cultural burguesa, que impôs a sua mimesis somática, fazendo do cotidiano uma rotina tautologicamente repetitiva, programada, previsível, automatizada.

\section{As subjetividades coletivas no processo de emancipação do novo constitucionalismo latino-americano}

A história recente da América Latina tem demonstrado que a busca pela emancipação humana não tem ocorrido à luz das previsões marxistas tradicionais, isto é, não sendo o proletário o ator social com potencialidade ínsita de redenção da humanidade. Ainda que grande parte da esquerda latino-americana ainda esteja aprisionada esquematicamente à ideia de que a classe trabalhadora é uma classe ontologicamente revolucionária, sendo o proletário o sujeito redentor da humanidade, investigando-se o processo político levado a efeito no novo constitucionalismo latinoamericano faz com que ao menos se questione esta tese.

O constitucionalismo latino-americano, expresso nas recentes Constituições da Bolívia e do Equador, promulgadas em 2008 e 2009, respectivamente, traz em seu bojo uma severa dose de participação popular na sua elaboração, tendo por objetivo a efetivação da doutrina do bien vivir. O conteúdo e a forma como os assuntos foram normatizados nas Constituições do Equador e da Bolívia denotam a ruptura com o 
eurocentrismo e com a importação de teorias dos países centrais, sendo talvez esta a principal característica desse movimento constitucionalista.

Ainda que hajam estudos abalizados acerca das implicações histórico-jurídicas que o constitucionalismo latino-americano ensejou, aqui importa observar quais subjetividades coletivas impulsionam o processo transformador que está em curso em alguns países da América Latina. Em substituição à figura do proletário tradicionalmente exposto na teoria marxista, diversos foram os intelectuais que opinaram sobre o surgimento de um novo ator político redentor, alguns deles se aproximando do contexto ora vivenciado na América Latina.

Jacob Gorender (1999, p. 231), por exemplo, entendia que os "assalariados intelectuais" é que constituiriam, no tempo presente, a classe que mais cresce e imprime o ritmo ao capital, tendendo a deixarem de ser estabilizadores da sociedade burguesa, convertendo-se em dirigentes de transformações profundas. Além disso, seriam eles os detentores de maior poder decisório sobre o processo de produção, isto é, o fator conhecimento. Ao mesmo tempo em que aposta nos trabalhadores intelectuais incluídos, Gorender dava por superada as teses que creditavam as esperanças sobre os socialmente excluídos.

Herbert Marcuse (1969, p. 54) já havia sinalizado à posição chave que esses trabalhadores intelectuais ocupam na escala produtiva, no entanto, permaneciam servos no plano da consciência. Ademais, ainda que ambos concordassem que o proletário, no sentido proposto por Marx e Engels, perdeu o seu impulso revolucionário, Marcuse sintetizou o seu argumento central em uma das últimas frases de uma grande obra sua, citando um amigo chamado Walter Benjamin (apud MARCUSE, 1967, p. 235): "Somente em nome dos desesperançados nos é dada esperança”. Marcuse (1969, p. 51) ponderou, ainda, que se deveria desconfiar é do potencial revolucionário dos estudantes, e não dos excluídos, tendo em vista que os discentes há tempos demonstram aversão à teoria marxista, nutrindo pouco interesse sobre a literatura revolucionária, demonstrando-se incapazes de formar lideranças políticas.

Slavoj Žižek (2011a, p. 81) tem uma posição firme acerca do personagem histórico que deveria subir ao palco para encerrar a sua pré-história. Alega que o problema central que enfrentou o marxismo ocidental foi a ausência de um agente ou sujeito revolucionário, dedicando-se a teoria à procura sempre inacabada dos demais atores sociais que pudessem fazer as vezes de sujeito revolucionário, diante da 
indisposição da classe operária. Mesmo autoadvertido, o esloveno caiu na mesma tentação dos intelectuais aqui citados, efetuando um esforço de previsão, conferindo aos excluídos o papel de redenção da humanidade.

Inicialmente, ratifica, no sentido de Marcuse e Gorender, que o proletário não é mais um sujeito com potência revolucionária, agregando que ele deixou de abarcar as pessoas necessitadas da sociedade. Coloca a questão de como pensar a universalidade do sujeito emancipatório, de modo não formal (determinado objetivamente), deixando o proletário de constituir a sua base substancial. Slavoj Žižek (2011b, p. 415-416) sustenta a negatividade como solução à questão: “[...] é o próprio capitalismo que oferece uma determinação substancial negativa, pois o sistema capitalista global é a 'base' substancial que medeia e gera os excessos (favelas, ameaças ecológicas etc.) que criam locais de resistência".

Em seguida, dispara: "E se a nova posição proletária for a dos favelados das novas megalópoles?” (ŽIŽEK, 2011, p. 419). Para defender a posição, socorre-se ao fato de que os favelados serão a maioria da população urbana, cujo crescimento ocorre à margem do controle estatal, vivendo em condições fora da legalidade. Insiste que, a par da necessidade de se esquivar da idealização dos favelados como formadores de uma nova classe revolucionária, as favelas são um dos poucos lugares eventuais autênticos, abarcado pelos excluídos dos benefícios da cidadania, sendo faticamente composta por aqueles que não têm nada a perder senão os seus grilhões, em alusão ao Manifesto (ŽIŽEK, 2011, p. 419-420).

Continua o seu argumento apontando que, surpreendentemente, os excluídos portam muitas das características do sujeito revolucionário marxiano, ao passo que são livres, formam um coletivo amplo, sendo privados dos modos de vida tradicionais. Finaliza a sua exposição sentenciando que:

\footnotetext{
Deveríamos procurar sinais das novas formas de consciência social que surgirão a partir dos coletivos das favelas: eles serão as sementes do futuro. $[\ldots]$

Na verdade, se a principal tarefa da política emancipatória do século XIX era romper o monopólio dos liberais burgueses com a politização da classe operária, e se a tarefa do século XX era despertar politicamente a imensa população rural da Ásia e da África, a principal tarefa do século XXI é politizar - organizar e disciplinar - as "massas desestruturadas" de favelados. (ŽIŽEK, 2011, p. 421-422) (grifou-se)
}

Herbert Marcuse (1972, p. 200-201), por sua vez, já havia levantado a tese de que nos países subdesenvolvidos existem requisitos primários ao socialismo, sendo um deles materializado na circunstância de que as classes dominantes são incapazes de 
desenvolver, sob seu dirigismo, as forças produtivas. Consequentemente, uma vez continuada a exploração indígena, a libertação nacional e revolução social poderiam coincidir com a libertação econômica. Esse parece ser justamente o argumento que ganha convalidação no contexto latino-americano recente.

Os processos constitucionais da América Latina, em especial no caso da Bolívia e do Equador, abriram vias ao surgimento de um ator social com potencial revolucionário, que demonstra essa confluência de fatores (a emancipação social dos índios cumulada com a libertação nacional econômica, exortando a política neoliberal), conforme alude Alejandro Médice (2012, p. 159-161): ${ }^{3}$

\begin{abstract}
Casos emblemáticos han sido los acaecidos en Bolivia e Ecuador ya que han tenido una alta incidencia en la movilización social contra el neoliberalismo adoptado por las clases políticas tradicionales de esos países y en consecuencia en los procesos constituyentes que han constitucionalizado nuevos principios, valores, derechos e imágenes constitucionales rectoras de la naturaleza en las recientes constituciones de Bolivia e Ecuador. [...] Estas movilizaciones impugnan las políticas neoliberales encuadradas en el Consenso de Washington y el paradigma desarrollistas extractivista tradicional, pero también las visiones de la izquierda urbana clasista, al contar con un fuerte componente de movimientos sociales que se referencian en las cosmovisiones de las comunidades originarias campesinas tanto de Bolivia como de Ecuador .
\end{abstract}

Ademais, a crença no potencial revolucionário dos excluídos terceiro-mundistas se mostrou um apontamento razoável à época, tanto que foi preciso diversas ditaduras militares para frear o avanço da transformação social imanente.

Portanto, reforça-se a tese de que não se pode pensar o constitucionalismo latino-americano como um levante do proletário, senão como um somatório de fatores, internos e externos, que culminou na negação explícita da incursão da racionalidade burguesa no campo social e político, refletindo inclusive no processo normativo. As Constituições da Bolívia e do Equador têm as marcas das suas formações sociais particulares, sendo o indígena o principal ator social político. Ainda que no mais das vezes ele possa também ser proletário, não foi ostentando a condição de trabalhador, ou vindicando direitos desta ordem, que ascenderam politicamente.

No caso latino-americano, portanto, o que se ergueu não foi uma consciência de classe aos moldes tradicionais, havendo a arregimentação de forças ao redor de um critério econômico-classista, senão está-se diante da repulsa objetivamente colocada pelo sujeito espoliado e oprimido, que por séculos amargurou o descompasso entre a sua condição e a sua cultura com o reflexo normativo. A legislação desses países é o

${ }^{3}$ Cf. BELLO, Enzo. A Cidadania no Constitucionalismo Latino-Americano. Caxias do Sul: Educs, 2012, p. 78-88; 106-126.

Em Debat: Rev. Dig., ISSNe 1980-3532, Florianópolis, n. 9, p. 40-55, jan-jun, 2013. 
resultado do esforço de romper com a visão viciada de importar as normas e concepções de mundo vigente nos países centrais, que apenas reforçam a submissão, passando a ostentarem um discurso de enaltecimento da sua cultura ancestral e sua própria condição.

Decerto não se está presenciando o proletário que se rebela perante a árdua situação de labor, senão um largo segmento social que sempre foi oprimido pela sua cor de pele, a qual se distancia do europeu espanhol, bem como que sempre teve colocada sobre si uma cultura que não correspondia as suas origens. $\mathrm{O}$ resgate das crenças antepassadas, cujas raízes se encontram em solo latino-americano e jamais foram plenamente arrancadas, significa o novo florescer da consciência indígena na condição de sabedouro da sua situação de espoliado, rechaçando as sempre presentes tentativas de incursão do modo de vida burguês, que impõe a sua racionalidade própria principalmente por meio da indústria cultural e dos aparelhos ideológicos.

Ainda que não coincida com a emancipação plena, o reconhecimento da condição indígena nas Constituições constitui a forma presente de emancipação parcial do índio dentro dos limites objetivos de participação política. Angaria esta subjetividade coletiva a sua forma especial de emancipação política, ao passo que considerá-lo meramente como "cidadão" abstrato não atendia aos mandamentos de particularização do seu status. O que parece estar suficientemente claro é que não se pode compreender o movimento constitucionalista recente como um levante popular do proletário, senão examiná-lo como parte de uma confluência de fatores em que a condição étnica coincide com uma crítica ao capital.

\section{Conclusão}

Caso se parta da lupa do marxismo tradicional, ainda se sustentará a crença de que o proletário - cujo termo carrega uma tremenda imprecisão - sempre será, ou ainda é, o ator social responsável por encabeçar o processo revolucionário. Levando em consideração o estágio atual da história, o qual revela a inexistência de vias abertas para uma emancipação humana plena, levando em consideração que o capitalismo não tem sido ameaçado como sistema econômico e ideologia dominantes, o constitucionalismo latino-americano desponta como oxigenação em um cenário de amplo conservadorismo global. 
Empreender esforços para interpretar os acontecimentos recentes como se fossem uma conquista do proletário sob o enfoque tradicional não apreende o fenômeno nas suas íntimas dimensões e, portanto, fica distante da essência, bem como da necessária visão de totalidade. O processo emancipatório que está em curso, ainda que não se saiba o seu alcance e em que medida avançará na superação da etapa do capitalismo, demonstrou que o somatório de dois fatores foram fundamentais para que se rompesse com o eurocentrismo até então dominante.

O primeiro deles é pensar a formação social específica dos povos, composta majoritariamente pela população indígena, de diversas tribos, as quais sofreram processo espoliativo pela incursão da racionalidade burguesa. Ou seja, apresenta-se uma fórmula social em que as intentadas padronizações de condutas, a partir dos ditames liberais, foram repelidas, apresentando-se como contraproposta um pensamento voltado para si, rompendo com a então tradicional visão de pensar inclusive o Direito com arrimo em lupas estrangeiras. $\mathrm{O}$ segundo aspecto é a presença direta de governantes que rechaçam, explicitamente, a ideologia proveniente do capitalismo global, havendo a repulsa à política até então vigente do neoliberalismo, cujo ápice regional se deu na década de 90.

Ainda que constitua um estudo de aproximação, o que parece estar suficientemente demonstrado é que como parte deste esforço de se afastar da importação automática de teorias eurocêntricas, que não traduzem as contradições que ganham forma na América Latina, não se pode compreender os processos constituintes recentes como um levante proletário. Frisa-se, por uma última vez, que a desaglutinação do proletário e da sua consciência no âmbito regional não permite que se faça esta afirmação. É preciso, portanto, romper com a dicotomia proletário versus burguês para compreender a totalidade do movimento constitucionalista latino-americano, notadamente porque é composto de ingredientes muito mais complexos, que dizem respeito à condição de indígena e de povo que teve a sua cultura ancestral sufocada por largos períodos da história. Constitui, portanto, um processo emancipatório de resgate das tradições, com alguma carga de crítica ao capital, no qual o indígena desponta como principal ator social transformador. 


\section{Referências bibliográficas}

DEBORD, Guy. A Sociedade do Espetáculo. Rio de Janeiro: Contraponto, 2012.

ENGELS, Friedrich. Do Socialismo Utópico ao Socialismo Científico. In: MARX, Karl; ENGELS, Friedrich. Obras Escolhidas. T. III; Lisboa/Moscovo:

Avante/Progresso, 1985.

GORENDER, Jacob. Marxismo Sem Utopia. São Paulo: Ática, 1999.

LINHARES, Hermínio. Contribuição à História das Lutas Operárias no Brasil. 2. ed. São Paulo: Alfa-Omega, 1977.

LÖWY, Michel. A Teoria da Revolução no Jovem Marx. São Paulo: Boitempo, 2012.

MARCUSE, Herbert. Ideologia da Sociedade Industrial. Rio de Janeiro: Zahar, 1967.

. O Fim da Utopia. Rio de Janeiro: Paz e Terra, 1969.

et. al. A Obsolescência do Marxismo. In: Opções da Esquerda. Rio de Janeiro:

Paz e Terra, 1972.

MARX, Karl. Crítica à Filosofia do Direito de Hegel - Introdução. São Paulo:

Boitempo, 2006.

Marx a Joseph Weydemeyer (em Nova Iorque), 5 de março de 1852. In:

MARX, Karl; ENGELS, Friedrich. Obras Escolhidas. T. I; Lisboa/Moscovo:

Avante/Progresso, 1982.

. Sobre a Questão Judaica. São Paulo: Boitempo, 2010.

MARX, Karl; ENGELS, Friedrich. A Sagrada Família. São Paulo: Boitempo, 2013.

MÉDICE, Alejando. La Constitución Horizontal: Teoría constitucional y giro decolonial. 2012.

MÉSZÁROS, István. Filosofia, Ideologia e Ciência Social. São Paulo: Boitempo, 2011.

Em Debat: Rev. Dig., ISSNe 1980-3532, Florianópolis, n. 9, p. 40-55, jan-jun, 2013. 
Para Além do Capital. São Paulo: Boitempo, 2012.

ŽIŽEK, Slavoj. Em Defesa das Causas Perdidas. São Paulo: Boitempo, 2011 b. Primeiro como Tragédia, Depois como Farsa. São Paulo: Boitempo, 2011 a. 